\title{
Involvement of meiotic resumption in the disruption of gap junctions between cumulus cells attached to pig oocytes
}

\author{
N. Isobe ${ }^{1}, T$. Maeda $^{2}$ and T. Terada ${ }^{2 *}$ \\ 'Animal Science, Graduate School for International Development and Cooperation, Hiroshima University, \\ Higashi-hiroshima 739-8529, Japan; and ${ }^{2}$ Animal Reproduction, Faculty of Applied Biological Science, \\ Hiroshima University, Higashi-hiroshima 739-8528, Japan
}

\begin{abstract}
The present study was undertaken to examine the mechanisms by which cumulus cells regulate meiotic resumption in pig oocytes using microinjections of lucifer yellow into cumulus-oocyte complexes combined with a fluorescent assay. Some cumulus-oocyte complexes cultured for $0,8,16,24,32,40$ and $48 \mathrm{~h}$ were denuded to assess the nuclear status of oocytes; the remaining complexes were injected with lucifer yellow and monitored for the transfer from the oocyte to the surrounding cumulus cells using confocal laser scanning microscopy. The proportion of oocytes undergoing germinal vesicle breakdown at 16,24 and $32 \mathrm{~h}$ of cultivation was much higher than that of cumulus-oocyte complexes in which all gap junctions within cumulus cells and between cumulus cells and oocyte were disrupted ( $16 \mathrm{~h}$ : $22.7 \%$ versus $8.8 \%, 24 \mathrm{~h}: 66.7 \%$ versus $40.3 \%, 32 \mathrm{~h}: 84.0 \%$ versus $69.4 \%$ ), showing that the disruption does not trigger meiotic resumption in the pig oocyte. A significant positive correlation $(r=0.99, P<0.01)$ was established between the proportion of germinal vesicle breakdown oocytes and that of cumulus-oocyte complexes exhibiting loss of gap junctions within all cumulus cell layers excluding the innermost layer. From these results, it is concluded that meiotic resumption in pig oocytes is induced by the disruption of gap junctions within cumulus cells, rather than that between the oocyte and cumulus cells, which blocks the conduction of meiosis inhibitory signals from the outer cumulus cells to the oocyte.
\end{abstract}

\section{Introduction}

Using electron microscopy, electrophysiological measurements and dye transfer experiments, Gilula et al. (1978) showed that, in the preovulatory and postovulatory cumulus-oocyte complexes (COCs) of rats, numerous small gap junctional contacts and bidirectional ionic coupling were present between cumulus cells and oocytes, although those gap junction contacts and the coupling were reduced as the time of ovulation approached. They postulated that cumulus-oocyte communication regulates the maturation of oocytes during follicular development before ovulation. Dekel and Beers (1980) also observed that germinal vesicle breakdown (GVBD) in rat denuded oocytes is accelerated in the presence or absence of $\mathrm{LH}$, and its time course is very similar to that of the cumulus-enclosed oocytes cultured in medium with gonadotrophin. They concluded that remisval of cumulus cells could mimic the effect of $\mathrm{LH}$ on spontaneous maturation by interrupting the communication between cumulus cells and oocyte. In addition, Dekel et al. (1981) found that meiotic arrest and cumulus-oocyte communication were maintained for at least $20 \mathrm{~h}$ when intact rat follicles were cultured in hormone-free medium. However, the

${ }^{*}$ Correspondence.

Received 28 August 1997. inclusion of LH in the culture medium resulted not only in the resumption of meiosis, but also in termination of the communication, suggesting that an interruption in the transmission of a substance from the cumulus to the oocytes, produced by exposing the COCs to gonadotrophins, allows meiosis to proceed. From these studies, it has been hypothesized that the interruption of cumulus-oocyte gap junctions leads to the relief of meiotic arrest (Tsafriri and Dekel, 1994).

According to Eppig (1982), who evaluated cumulus-oocyte communication by incorporating $\left[{ }^{3} \mathrm{H}\right]$ uridine and $\left[{ }^{3} \mathrm{H}\right]$ choline into COCs, maturation of rat oocytes is already initiated by $3 \mathrm{~h}$ after hCG injection, whereas gap junctions between oocyte and cumulus cells were not disrupted at 3 and $6 \mathrm{~h}$ after hCG injection. A similar observation was reported by Salustri and Siracusa (1983) who demonstrated that at $3 \mathrm{~h}$ of culture of mouse COCs in the presence of FSH, the metabolic coupling remained high but meiotic maturation had already resumed. Larsen et al. $(1986,1987)$ observed a close temporal correlation between the loss of cumulus cell-cumulus cell gap junctions, rather than cumulus-oocyte gap junctions, and the resumption of meiotic maturation in superovulated rats. These results have emphasized that gap junction loss within the cumulus cells per se induces the resumption of oocyte meiosis in rodents. However, the precise mechanism of this gap junction lossdependent meiotic resumption is unclear, although a gap 
junction loss independent pathway was reported by Byskov et al. (1997).

In pigs, Motlik et al. (1986) provided evidence that the oocyte and corona radiata (the innermost cumulus cells) remain tightly coupled, even when the oocyte has already resumed meiosis. However, to date, the precise role that cumulus cells play in the resumption of meiosis in pig COCs has not been fully elucidated. The aim of the present study was to investigate the regulatory mechanisms involved in meiotic resumption in pig oocytes by determining the timing of the disruption of cell-cell gap junctions using a fluorescent dye (lucifer yellow).

\section{Materials and Methods}

\section{General procedures}

Ovaries were collected from prepubertal gilts at a local abattoir and were transported to the laboratory in $0.85 \%(\mathrm{w} / \mathrm{v})$ $\mathrm{NaCl}$ with $0.1 \mathrm{mg}$ kanamycin $\mathrm{ml}^{-1}$ (Meiji Seika, Tokyo) at about $35^{\circ} \mathrm{C}$ within $2 \mathrm{~h}$. Oocytes were collected from follicles $3-9 \mathrm{~mm}$ in diameter with a 21 gauge needle attached to a disposable $10 \mathrm{ml}$ syringe. Oocytes possessing a complete and compact cumulus mass were selected and washed twice in Dulbecco's PBS supplemented with 5\% bovine serum (Nacalai Tesque, Kyoto) and $0.1 \mathrm{mg}$ kanamycin $\mathrm{ml}^{-1}$. They were further washed several times in the culture medium. Ten to fifteen COCs were transferred to a droplet of $100 \mu \mathrm{I}$ of culture medium covered with warm mineral oil (E. R. Squibb and Sons, Inc. Princeton, NJ) in a $35 \mathrm{~mm}$ polystyrene culture dish and cultured for $0,8,16,24,32,40$ and $48 \mathrm{~h}$ at $39^{\circ} \mathrm{C}$ in a humidified atmosphere of $5 \% \mathrm{CO}_{2}$ in air. The culture medium was TCM-199 with Earle's salts (Gibco BRL, Grand Island, NY)

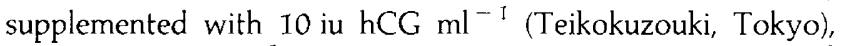
$10 \mathrm{iu}$ PMSG $\mathrm{ml}^{-1}$ (Teikokuzouki), $1 \mu \mathrm{g}$ oestradiol $\mathrm{ml}^{-1}$ (Sigma Chemical Co., St Louis, MO), $50 \mu \mathrm{g}$ gentamicin sulfate $\mathrm{ml}^{-1}$ (Sigma) and 10\% fetal calf serum (Gibco). The medium was sterilized by filtration through $0.45 \mu \mathrm{m}$ Millipore filters (Millipore Ltd, Bedford, MA).

After a given period of cultivation, some of the COCs were denuded mechanically for determination of meiotic status using a finely drawn Pasteur pipette and the remainder of the COCs was prepared for the dye transfer test. The denuded oocytes were fixed for $48 \mathrm{~h}$ in acetic acid: ethanol $(1: 3, \mathrm{v} / \mathrm{v})$ at $10^{\circ} \mathrm{C}$, and stained with $1 \%(\mathrm{v} / \mathrm{W})$ lacmoid in $45 \%(\mathrm{v} / \mathrm{v})$ acetic acid for examination by phase-contrast microscopy. The oocytes were classified according to the method of Hunter and Polge (1966) as having an intact germinal vesicle (GV) or having undergone germinal vesicle breakdown (GVBD).

\section{Dye transfer experiments}

Oocytes surrounded by cumulus cells were injected with $10 \mathrm{mmol}$ Hepes $1^{-1}$ containing $10 \%(\mathrm{w} / \mathrm{v})$ lucifer yellow $\mathrm{CH}$ (Sigma) after incubations of $0,8,16,24,32,40$ and $48 \mathrm{~h}$ on a heated stage $\left(37^{\circ} \mathrm{C}\right)$ of an inverted microscope at $\times 100$ magnification using a Hoffmann Modulation contrast system (Modulation Optics Inc., Greenvale, NY). The holding and injection pipettes were made by drawing glass capillary tubes with a pipette puller (Model PC-84, Sutter Instrument Company, Novato, $(A)$ and were further processed on a micropipette beveler (Model BV-10, Sutter Instrument Company) and a microforge (WILDM3D, Leica, Heerbrugg). The outer and inner diameters of the holding and injection pipettes were 150 and $120 \mu \mathrm{m}$, and 10 and $7 \mu \mathrm{m}$, respectively. The injection pipette had a bevel angle of $35^{\circ}$ and a sharp spike to assist penetration through the oolemma. The holding and injection pipettes were fixed to a tool holder and were connected to a microinjector (CIJ-1; Shimadzu, Kyoto). The injection press and duration were $20-30 \mathrm{kPa}$ and $0.05 \mathrm{~s}$, respectively and $4 \mathrm{pl}$ of lucifer yellow solution was injected into each oocyte. The volume of the injected solution was calculated on the basis of the diameter of a droplet of the solution expelled from the injection pipette into mineral oil. During injection and subsequent fluorescent observation, COCs were kept in PBS containing $5 \%(\mathrm{v} / \mathrm{v})$ bovine serum. The spread of the dye into surrounding cumulus cells was monitored using confocal laser scanning microscopy (ACAS 570, Meridian Instruments, Inc., Okemos, MI) with a $\times 100$ oil objective. An argon ion laser adjusted at $488 \mathrm{~nm}$ wavelength was used. The emitted light was separated by a dichroic mirror (575SP); a 530/30 band pass filter was placed in front of the detector. The scanning was carried out in the section where the largest diameters of oocytes were observed at a field depth of about $14.5 \mu \mathrm{m}$. No oocytes were damaged by the injection of lucifer yellow solution, although degenerated oocytes at the time of injection could not be used because the injected lucifer yellow spilled out of these oocytes easily due to disintegration of their ooplasms. However, observation of the lucifer yellow fluorescence more than $15 \mathrm{~min}$ after injection showed a spontaneous spilling of lucifer yellow out of the oocytes, so the fluorescent monitoring was carried out within 15 min after injection.

Cumulus-oocyte complexes were classified into four categories according to the degree of dye transferred into the cumulus cells: category 1 , the dye was transferred to all layers of cumulus cells surrounding oocytes (Fig. Ia); category 2, the dye was transferred to more than two inner layers of cumulus cells but not all layers of the cumulus cells (Fig. 1b); category 3, the dye was transferred only to the innermost layer of cumulus cells (Fig. Ic); and category 4, the dye was not transferred to cumulus cells (Fig. 1d).

\section{Statistical analysis}

Each experiment was replicated at least three times. The data from each experiment were pooled for presentation and a chi-squared analysis was used to test significance among groups. The percentage data were subjected to arc sine transformation before correlation analyses were carried out using Student's t test. A probability of $P<0.05$ was considered to be statistically significant.

\section{Results}

Time course of germinal vesicle breakdown in pig cumulus-oocyte complexes cultured in vitro

Cumulus-oocyte complexes cultured for $0-48 \mathrm{~h}$ were denuded and their nuclear configuration was observed to 

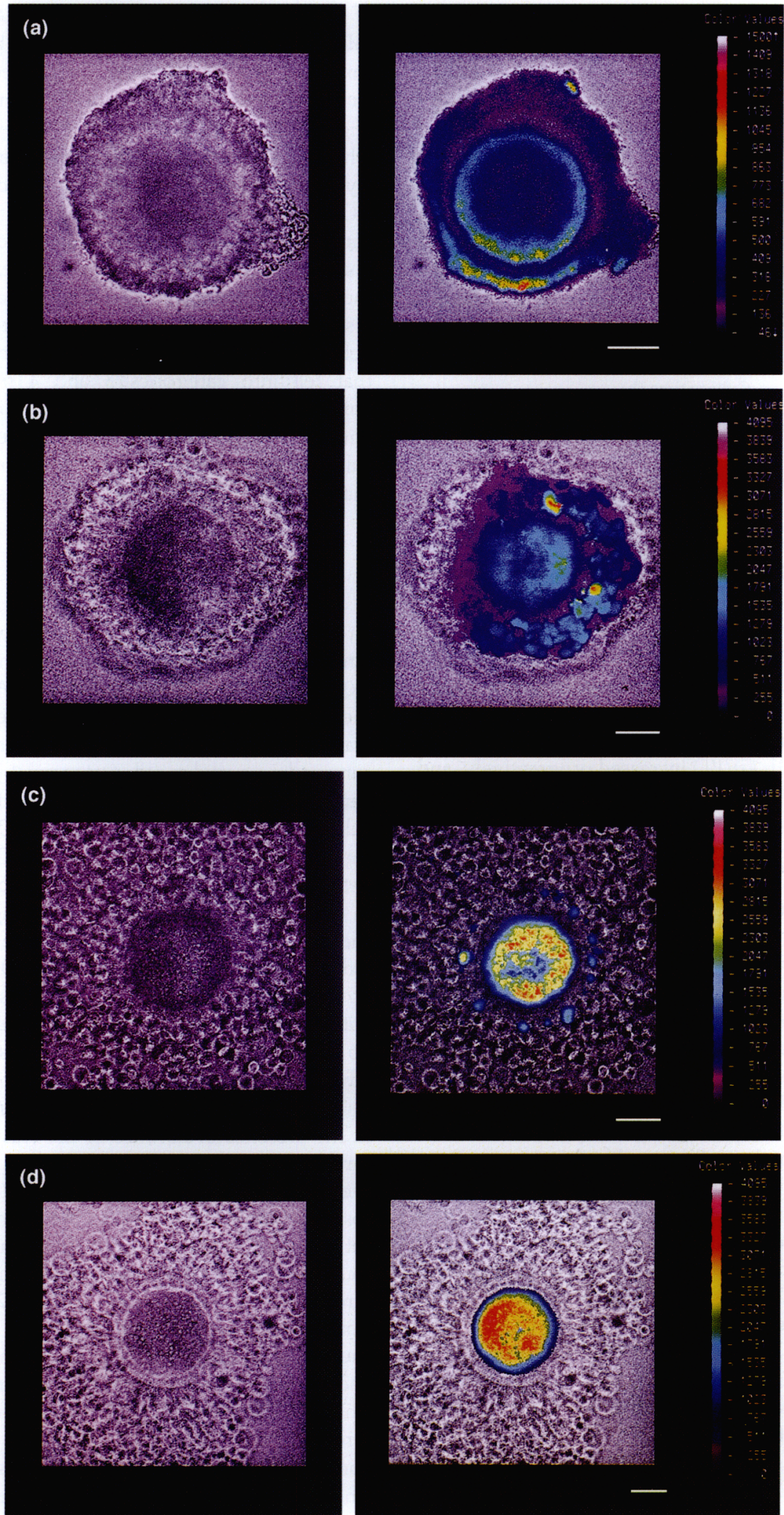

Fig. 1. Light micrographs (left) and confocal laser scanning microscopic images (right) of various categories of lucifer yellow transfer in pig cumulus-oocyte complexes. (a) Category 1, dye transferred to all layers of cumulus cells surrounding oocytes. (b) Category 2 , dye transferred to more than two inner layers of cumulus cells but not all layers of the cumulus cells. (c) Category 3 , dye transferred only to the innermost layer of cumulus cells. (d) Category 4, dye not transferred to cumulus cells. Scale bars represent $50 \mu \mathrm{m}$. 


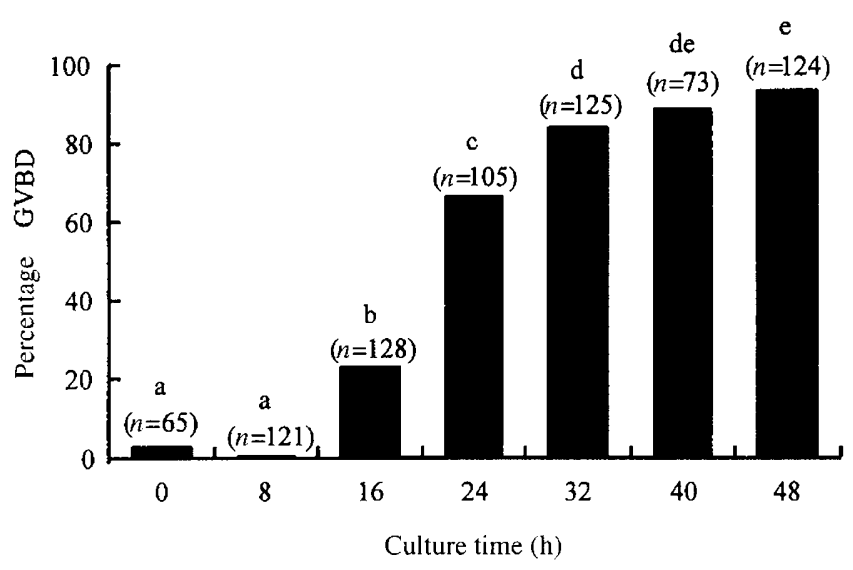

Fig. 2. Time course of germinal vesicle breakdown (GVBD) in pig cumulus-oocyte complexes cultured in vitro. Values with different superscripts are significantly different $(P<0.05)$.

explore the relationship between the loss of intercellular communication and induction of meiotic resumption. The proportion of oocytes undergoing GVBD at the various culture times are shown (Fig. 2). Up to $8 \mathrm{~h}$ of culture, most oocytes ( 63 of 65 at $O \mathrm{~h}$ and 120 of 121 at $8 \mathrm{~h}$ ) were at GV stage. After $16 \mathrm{~h}$ of cultivation, GVBD had occurred in $22.7 \%$ of the oocytes (29 of 128). The incidence of GVBD significantly increased after $24 \mathrm{~h}$ cultivation. With further culture, the proportion of oocytes with GVBD increased progressively, and reached $93.5 \%$ (116 of 124 ) after $48 \mathrm{~h}$ of culture.

\section{Transfer of the lucifer yellow from oocytes to cumulus cells}

After $0-48 \mathrm{~h}$ of culture, COCs were injected with lucifer yellow and the degree of dye transferred from oocytes to cumulus cells was observed (Table 1). When oocytes at the onset and after $8 \mathrm{~h}$ of cultivation were injected with lucifer yellow, the dye was transferred into all cumulus cells surrounding oocytes in more than $90 \%$ of COCs (category 1). After $16 \mathrm{~h}$ of cultivation, the proportion of COCs in category 1 had significantly decreased. In oocytes microinjected with lucifer yellow after $16 \mathrm{~h}$ of cultivation the dye was transferred into more than two inner cumulus cell layers but not to outermost cumulus cells (category 2 ) in $61.8 \%$ of COCs. The COCs in category 3 (dye transferred only to the innermost layer of cumulus cells) and category 4 (no dye transferred to cumulus cells) were first observed after $16 \mathrm{~h}$ of cultivation. After $24 \mathrm{~h}$ of cultivation, $40 \%$ of COCs showed no transport of lucifer yellow from oocytes to cumulus cells. When COCs were cultured for more than $32 \mathrm{~h}$, none was recorded in category 1 . The proportions of COCs in category 4 increased from $8.8 \%$ of COCs at $16 \mathrm{~h}$ of cultivation to $92.1 \%$ of COCs at $40 \mathrm{~h}$ of cultivation. After $48 \mathrm{~h}$ of cultivation, all COCs were found to be in category 4 .

\section{Relationship between germinal vesicle breakdown and the degree of} the disruption of cumulus-cumulus cell or oocyte-cumulus cell gap junctions

The time course of the proportion of GVBD oocytes, the total number of category 2, 3 and $4 \mathrm{COCs}$, the total numbers of category 3 and 4 COCs and category 4 COCs were calculated at each time of cultivation to examine the relationship between GVBD and the degree of the disruption of cumulus-cumulus cell or oocyte-cumulus cell gap junctions (Fig. 3). Category 2, 3 and 4 COCs represent the COCs in which gap junctions within at least the outermost cumulus cell layers were disrupted. Category 3 and 4 COCs represent the COCs in which the gap junctions from within the outer cumulus layer to at least two inner layers of cumulus cells were disrupted. Category 4 COCs represent the COCs in which the gap junctions between oocytes and cumulus cells were disrupted. A significant positive correlation was established between the proportion of GVBD oocytes and those COCs that fell into categories 3 and $4(r=0.99, P<0.01)$. The temporal pattern of COCs in category 4 was delayed compared with that of GVBD oocytes. However, after 40 and $48 \mathrm{~h}$ of cultivation, the proportions of category $4 \mathrm{COCs}$ were higher than the proportion of GVBD oocytes.

\section{Discussion}

At the onset and after $8 \mathrm{~h}$ of cultivation, disruption of gap junctions between the outermost cumulus cells was found in 9.0 and $8.5 \%$ of COCs, respectively. After $16 \mathrm{~h}$ of cultivation, the proportion of COCs in which the injected lucifer yellow was transferred through the gap junction from oocytes to all surrounding cumulus cells (category 1 COCs) was significantly decreased compared with the proportion after 0 and $8 \mathrm{~h}$ of culture. However, cultivation of COCs for $16 \mathrm{~h}$ resulted in a significantly higher proportion of COCs in which gap junctions between cumulus cells was disrupted (category 2 and 3 COCs). In agreement with the present findings, Motlik et al. (1986) showed that the uptake of $\left[{ }^{3} \mathrm{H}\right]$ uridine as well as the coupling index decreased markedly in pig COCs cultured in vitro for $16 \mathrm{~h}$. These results indicate that the disruption of gap junctions within the cumulus cells in pig COCs is initiated between 8 and $16 \mathrm{~h}$ of cultivation and the progression of this uncoupling advanced very rapidly toward $16 \mathrm{~h}$.

The observation that GVBD in denuded rat oocytes cultured in the presence or absence of $\mathrm{LH}$ was accelerated and that its timing was very similar to that of COCs cultured in the presence of LH, led Dekel and Beers (1980) to suggest that LH fostered maturation of the oocyte by interrupting its communication with the cumulus oophorus. Similarly, Dekel et al. (1981) found that both cumulus-oocyte communication and meiotic arrest were maintained for at least $20 \mathrm{~h}$ of culture without gonadotrophin. However, exposure of rat oocytes to LH caused the interruption of ionic coupling between cumulus cells and the oocyte and induced the resumption of meiosis. Therefore, they concluded that the maintenance of meiotic arrest may be dependent upon the integrity of cell-to-cell communication between the cumulus cells and the oocyte. These studies strongly suggest that the disruption of communication between cumulus cells and the oocyte leads to the GVBD of the oocyte.

However, in the present study, the proportion of oocytes undergoing GVBD at 16, 24 and $32 \mathrm{~h}$ of cultivation was much higher than the proportion of COCs in category 4 (16 h: $22.7 \%$ versus $8.8 \%, 24 \mathrm{~h}$ : $66.7 \%$ versus $40.3 \%, 32 \mathrm{~h}: 84.0 \%$ versus 
Table 1. Time course of lucifer yellow transfer in pig cumulus-oocyte complexes (COCs)

\begin{tabular}{|c|c|c|c|c|c|c|}
\hline \multirow{2}{*}{$\begin{array}{l}\text { Duration } \\
\text { of culture } \\
\text { (h) }\end{array}$} & \multirow{2}{*}{$\begin{array}{c}\text { Number } \\
\text { of } \\
\text { COCs }\end{array}$} & \multicolumn{5}{|c|}{ Category (\%) } \\
\hline & & 1 & 2 & 3 & & 4 \\
\hline 0 & 100 & $91(91.0)^{\mathrm{a}}$ & $9(9.0)^{a}$ & $0(0.0)^{a}$ & 0 & $(0.0)^{\mathrm{a}}$ \\
\hline 8 & 71 & $65(91.5)^{\mathrm{a}}$ & $6(8.5)^{a}$ & $0 \quad(0.0)^{\mathrm{a}}$ & 0 & $(0.0)^{\mathrm{a}}$ \\
\hline 16 & 68 & $12(17.6)^{b}$ & $42(61.8)^{\mathrm{b}}$ & $8(11.8)^{b c}$ & 6 & $(8.8)^{b}$ \\
\hline 24 & 77 & $6(7.8)^{b}$ & $28(36.4)^{c}$ & $12(15.6)^{\mathrm{bd}}$ & 31 & $(40.3)^{c}$ \\
\hline 32 & 72 & $0 \quad(0.0)^{c}$ & $4(5.6)^{\mathrm{ad}}$ & $18(25.0)^{\mathrm{d}}$ & 50 & $(69.4)^{d}$ \\
\hline 40 & 63 & $0 \quad(0.0)^{c}$ & $2 \quad(3.2)^{\mathrm{ad}}$ & $3(4.8)^{\mathrm{ac}}$ & 58 & $(92.1)^{\mathrm{e}}$ \\
\hline 48 & 66 & $0 \quad(0.0)^{c}$ & $0 \quad(0.0)^{d}$ & $0 \quad(0.0)^{\mathrm{a}}$ & & $(100.0)^{f}$ \\
\hline
\end{tabular}

Category I, dye transferred to all layers of cumulus cells surrounding oocytes; category 2, dye transferred to more than two inner layers of cumulus cells but not all layers of the cumulus cells; category 3, dye transferred only to the innermost layer of cumulus cells; category 4 , dye not transferred to cumulus cells.

a.b.,.d.,.fValues with different superscripts within a column are significantly different $(P<0.05)$.

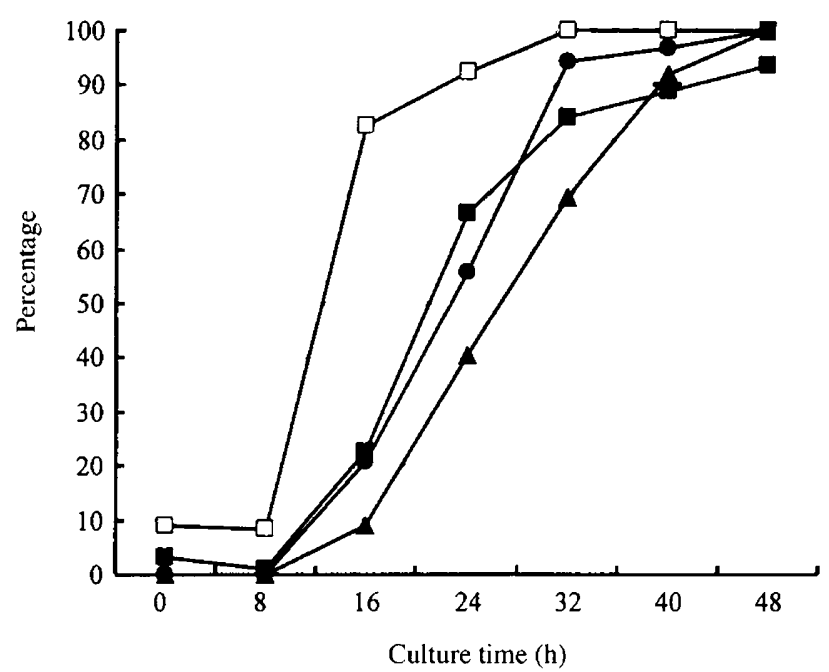

Fig. 3. Relationship between germinal vesicle breakdown (GVBD) of pig oocytes and the degree of the lucifer yellow dye transfer in pig cumulus-oocyte complexes (COCs). $\mathbf{\square}$, Percentage of GVBD oocytes; $\square$, percentage of COCs exhibiting 2,3 and 4 degree of dye transfer; - percentage of COCs exhibiting 3 and 4 degree of dye transfer; $\boldsymbol{\Delta}$, percentage of COCs exhibiting 4 degree of dye transfer. Category 1, dye transferred to all layers of cumulus cells surrounding oocytes; category 2, dye transferred to more than two inner layers of cumulus cells but not all layers of the cumulus cells; category 3, dye transferred only to the innermost layer of cumulus cells; category 4, dye not transferred to cumulus cells.

69.4\%). This finding indicates that the disruption of the gap junctions between cumulus cells and the oocyte is preceded by the meiotic resumption of the oocyte. Therefore, the disruption of the cumulus-oocyte gap junctions does not lead to the resumption of meiosis in the pig COCs.

A significant positive correlation $(r=0.99, P<0.01)$ was established between the proportion of GVBD oocytes and the proportion of COCs in either category 3 or 4 . Since all gap junctions within cumulus cells except for those of the inner layer had disappeared in COCs in categories 3 and 4, the correlation reveals that the meiotic resumption in pig oocytes involves the disruption of gap junctions within cumulus cells rather than those between the oocyte and cumulus cells. Similar conclusions that the losses of cumulus-to-cumulus cell gap junction preceded the induction of meiotic resumption have been derived from studies with rat COCs in vivo (Larsen et al., 1986, 1987) and in vitro (Wert and Larsen, 1989), and mouse COCs in vivo (Eppig, 1982).

Larsen et al. (1986, 1987), who compared the degree of gap junctional cell-to-cell interaction in several distinct regions of the rat follicle at various times during the preovulatory period by using a more direct quantitative freeze-fracture analysis, have provided evidence that, although a small decrease in the mean area of membrana gap junctions was noted, the area of cumulus cell gap junctions was markedly reduced $2-3 \mathrm{~h}$ after an ovulatory injection of hCG (the time of meiotic resumption in the oocytes). Considering other experiments in which inhibition of meiotic maturation by membrana granulosa cells in isolated COCs has been demonstrated (Tsafriri and Channing, 1975; Sato and Ishibashi, 1977; Sirard and Bilodeau, 1990a, b; Larsen et al., 1986, 1987) suggested that the cumulus oophorus regulates the conduction of meiosis inhibitory signals from the membrana granulosa to oocyte in vivo. In addition, quantitative freeze-fracture analysis in rat COCs by Wert and Larsen (1989) showed that downregulation of cumulus cell gap junctions was initiated before meiotic resumption under various in vitro conditions. These results supported the earlier suggestion (Larsen et al., 1986, 1987) that gap junction loss within the cumulus oophorus is instrumental in releasing the oocyte from the inhibitory influence of membrana granulosa cells so that meiotic maturation can be initiated in intact preovulatory follicles.

However, since COCs without membrana granulosa cells were examined in the present study, it is clear that oocyte meiotic resumption is not induced by terminating the transmission of an inhibitory factor from granulosa cells. Moreover, Isobe et al. (1996) reported that the culture of denuded oocytes for a further $24 \mathrm{~h}$, after the removal of their cumulus cells after $24 \mathrm{~h}$ of cultivation, significantly increased the proportion of oocytes undergoing GVBD (90\%) compared with oocytes cultured continuously for $48 \mathrm{~h}$ without removing the cumulus cells $(80 \%)$, and that the amount of GVBD of denuded oocytes co-cultured with $\mathrm{COCs}$ for a second $24 \mathrm{~h}$ of cultivation was 
similar to that of denuded oocytes cultured without COCs ( $93 \%$ and $88 \%$, respectively). From these results, Isobe et al. (1996) suggested that the cumulus cells surrounding pig oocytes cultured in vitro suppress GVBD, and that the suppressive factor produced by the cumulus cells is transferred to the oocytes through gap junctions. Therefore, the cumulus cells cultured in vitro in the present study might also have produced the GVBD suppressive factor, since the present culture system was similar to that used by Isobe et al. (1996). Furthermore, on the basis of the conclusion that the disruption of gap junctions within cumulus cells evokes meiotic resumption, which is derived from the evidence of a significant positive correlation between the proportion of GVBD oocytes and the proportion of category 3 and 4 COCs, the meiotic inhibitory signal must be produced by all cumulus cell layers except the innermost layer. This suggestion is supported by the evidence that, when COCs were cultured in a medium supplemented with various concentrations of conditioned medium (prepared previously by culturing $20 \mathrm{COCs}$ in $10 \mu \mathrm{l}$ droplet), increasing the concentrations of the medium reduced both the proportion of GVBD oocytes and the proportion of COCs in which some of the outermost layers of cumulus cells were expanded ( $\mathrm{N}$. Isobe, T. Maeda and T. Terada, unpublished).

Even at the onset of cultivation, a low frequency of oocytes undergoing GVBD was observed (3.1\%) despite the application of strict oocyte selection criteria. This result was consistent with the study by Motlik and Fulka (1976), who found that some oocytes had already undergone GVBD immediately after isolation from ovaries. These oocytes undergoing GVBD before cultivation seem to be isolated from atretic follicles since the progression of atresia is accompanied by nuclear maturation of the oocyte in those follicles (Ingram, 1962). In the present study at the onset of cultivation, the lucifer yellow injected into the oocyte was not transferred to all layers of cumulus cells in part of COCs $(9.0 \%)$. On the basis of the conclusion that the disruption of gap junctions within cumulus cells induced the meiotic resumption, this GVBD before cultivation may be due to the interruption of transfer through gap junctions that is independent of the cumulus cell expansion, since only oocytes with unexpanded cumulus cells were used in the present study. This hypothesis is supported by the fact that a decrease in the gap junction permeability is the result of the phosphorylation of connexin 43 , one of gap junction proteins (Granot and Dekel, 1994).

The authors would like to acknowledge A. J. Hackett, retired and formerly from the Centre for Food and Animal Research, Agriculture Canada, Ottawa, Canada, for his kindly help in reviewing the manuscript and also the staff of the Meat Inspection Office in Onomichi and Fukuyama for supplying the pig ovaries.

\section{References}

Byskov AG, Andersen CY, Hossaini A and Guoliang X (1997) Cumulus cells of oocyte-cumulus complexes secrete a meiosis-activating substance when stimulated with FSH Molecular Reproduction and Development 46 296-305

Dekel N and Beers WH (1980) Development of rat oocytes in vitro: inhibition and induction of maturation in the presence or absence of cumulusoophorus Developmental Biology 75 247-254

Dekel N, Lawrence TS, Gilula NB and Beers WH (1981) Modulation of cell-tocell communication in the cumulus-oocyte complex and the regulation of oocyte maturation by LH Developmental Biology 86 356-392

Eppig JJ (1982) The relationship between cumulus-oocyte coupling, oocyte meiotic maturation, and cumulus expansion Developmental Biology 89268 272

Gilula NB, Epstein ML and Beers WH (1978) Cell-to-cell communication and ovulation: a study of the cumulus-oocyte complex Journal of Cell Biology 78 58-75

Granot I and Dekel N (1994) Phosphorylation and expression of connexin-43 ovarian gap junction protein are regulated by luteinizing hormone Journal of Biological Chemistry $26930502-30509$

Hunter RHF and Polge C (1966) Maturation of follicular oocytes in the pig after injection of human chorionic gonadotrophin Journal of Reproduction and Fertility 12 525-531

Ingram DL (1962) Atresia. In The Ovary Vol. I pp 247-274 Ed S Zuckerman. Academic Press, New York

Isobe N, Fujihara M and Terada T (1996) Curnulus cells suppress meiotic progression in pig oocytes cultured in vitro. Theriogenology 45 $1479-1489$

Larsen WJ, Wert SE and Brunner GD (1986) A dramatic loss of cumulus cell gap junction is correlated with germinal vesicle breakdown in rat oocytes Developmental Biology 113 517-521

Larsen WJ, Wert SE and Brunner GD (1987) Differential modulation of follicle cell gap junction populations at ovulation Developmental Biology 122 61-71

Motlik J and Fulka J (1976) Breakdown of the germinal vesicle in pig oocytes in vivo and in vitro. Journal of Experimental Zoology 198 155-162

Motlik J, Fulka J and Flechon JE (1986) Changes in intercellular coupling between pig oocytes and cumulus cells during maturation in vivo and in vitro. Journal of Reproduction and Fertility 76 31-37

Salustri A and Siracusa G (1983) Metabolic coupling, cumulus expansion and meiotic resumption in mouse cumuli oophori cultured in vitro in the presence of FSH or dbcAMP, or stimulated in vivo by hCG journal of Reproduction and Fertility 68 335-341

Sato E and Ishibashi T (1977) Meiotic arresting action of the substance obtained from cell surface to porcine ovarian granulosa cells Japan Journal of Zootechnical Science 48 22-26

Sirard MA and Bilodeau S (1990a) Granulosa cells inhibit the resumption of meiosis in bovine oocytes in vitro. Biology of Reproduction 43 777-783

Sirard MA and Bilodeau S (1990b) Effects of granulosa cell co-culture on in vitro meiotic resumption of bovine oocytes Journal of Reproduction and Fertility $\mathbf{8 9}$ 459-465

Tsafriri A and Channing CP (1975) An inhibitory influence of granulosa cells and follicular fluid upon porcine meiosis in vitro. Endocrinology 96 922-927

Tsafriri A and Dekel N (1994) Molecular mechanisms in ovulation. In Molecular Biology of the Female Reproductive System pp 207-258 Ed. JK Findlay. Academic Press, San Diego

Wert SE and Larsen WJ (1989) Meiotic resumption and gap junction modulation in the cultured rat cumulus-oocyte complex Gamete Research 22 $143-162$ 